\title{
Designing Clusters of Distribution Area and Delivery Route for Maximizing the Vehicle Utilization and Minimizing the Workload Gap and Transportation Cost
}

\author{
Amelia Santoso \\ Department of Industrial Engineering, Faculty of Engineering \\ University of Surabaya, Indonesia \\ Email: amelia@staff.ubaya.ac.id (Corresponding Author) \\ Joniarto Parung \\ Department of Industrial Engineering, Faculty of Engineering \\ University of Surabaya, Indonesia \\ Dina Natalia Prayogo \\ Department of Industrial Engineering, Faculty of Engineering \\ University of Surabaya, Indonesia \\ Winardi \\ Department of Industrial Engineering, Faculty of Engineering \\ University of Surabaya, Indonesia
}

\begin{abstract}
This paper deals with determining vehicle routes in product distribution from a distributor to a large number of retailers in a vast distribution area. To determine the vehicle routes in a vast distribution area and a large number of retailers that have to be served causes the VRP model to become complicated. Therefore, this paper applies the cluster firstroute second concept to design a distribution system in two stages. The first stage is to cluster the distribution area based on the distance between retailers. The second stage is to determine a vehicle route for each cluster using the multiobjective vehicle routing problem with time window and balanced driver workload (VRPTWBW) approach. The proposed VRPTWBW model has three objectives, i.e., (i) to minimize the number of assigned vehicles, (ii) to minimize the total delivery time, and (iii) to balance the driver workload. This second stage starts once the clusters of the distribution area are set. Contrasted with the current practice in the company, this proposed model offers the significant impacts: (i) the reduction of workload gap among driver about $29 \%$ (from 2.59 hours to 1.83 hours); (ii) the increased of vehicle utility by $44 \%$ (from $30 \%$ to $43 \%$ ), and (iii) the increase savings of twoweek course fees of IDR. 11 million (about $23.84 \%$ ).
\end{abstract}

Keywords: cluster first-route second, VRP time windows balance workload, distribution systems, workload balance

\section{INTRODUCTION}

The distributor and retailers are intermediaries in the distribution concept that have a role to distribute the products from the manufacturer to end customers (Chopra, 2019). A distributor can achieve high performance if the distributor delivers all retailer orders quickly (Das et al., 2021) or on time with minimum total costs (Goetschalckx, 2011). Therefore, transportation is one of the critical success key factors of the distribution system to ensure the delivery is on time (Ravindran and Warsing Jr, 2013). According to NevesMoreira et al. (2016), there are two types of transportation, i.e., long-haul transportation and short-haul transportation. Generally, long-haul transportation is used to deliver the products from manufacturer to distributor when short-haul transportation for delivering the products from distributor to retailers (Ghiani et al., 2004). This paper focuses on shorthaul transportation.

According to Ghiani et al. (2013), short-haul transportation is usually used to deliver products to many retailers in a relatively small-sized geographic area. Generally, the demand size of each retailer is less than truckload capacity so the distributor will deliver several retailers' demand using sharing shipping concepts. In sharing shipping. In the sharing shipping, the demand of multiple retailers is often delivered using LTL (less than truckload) or TL (truckload) carrier with multi stops (Cortes and Suzuki, 2020). The vehicle can load the demand of multi retailers as long as the vehicle capacity is still sufficient. Thus, the vehicle will visit several places to deliver the demand of retailers (Neves-Moreira et al., 2016). Hence, the sharing shipment problem in the product distribution focuses on optimizing the vehicle route (Braekers et al., 2016). The purpose of this paper is to determine the optimal routes of 
assigned vehicles in distributing products from one distributor to geographically dispersed retailers.

The optimal routes of assigned vehicles to distribute products from one or multiple distributors to geographically dispersed retailers can be determined by applying the concepts of the vehicle routing problem (VRP) (Laporte et al., 1988). According to Daneshzand (2011), Chen (2018) and Liao et al. (2017), the VRP determines a set of routes that starts and ends at the distributor minimizing the transportation cost and fulfilling the customer demands and operational constraints. As stated by Goetschalckx (2011), the simplest of the vehicle routing problems (VRP) is the traveling salesman problem (TSP) that determines the route of a single vehicle without vehicle capacity constraint. In reality, we can only load products less than or equal to the vehicle capacity. In research growth, many researchers such as Toth and Vigo (2002), Lei et al. (2011), and Jin et al. (2014) have considered the vehicle capacity constraint in the developed model called capacitated VRP (CVRP). In CVRP, a distributor delivers homogeneous products to several customers geographically separated using identical vehicles with limited capacity.

Besides CVRP, there are many kinds of VRP researched. One of other VRP variants is VRP that considers time window (Baldacci et al., 2012; Braekers et al., 2016; Pérez-rodríguez, and Hernández-aguirre, 2019). According to Miranda and Conceição (2016), in the vehicle routing problem with time windows (VRPTW), the vehicles are only allowed to start serving each retailer at the earliest time windows. Each vehicle has to return to the distributor before the latest time windows (El-Sherbeny, 2010). Due to the imbalanced load of each vehicle, Lee and Ueng (1999) considered the balanced load of each vehicle in the VRP model. Nevertheless, the VRP model did not consider the time window constraint. According to Mancini et al. (2021) and Matl et al. (2017), the workload can be measured by the number of customers visited by the driver or vehicle, the amount of delivered load, or the tour length. Kritisos and Ioannou (2010) developed the VRPTW model by considering the balance of loads carried by each vehicle. Even though Kritisos and Ioannou (2010) have balanced a load of vehicles carried, they cannot guarantee that the workload of each driver is balanced. If the number of consumers visited by vehicles is not the same, each vehicle has different travel times. It causes an imbalanced driver workload for each vehicle. Therefore, this paper uses the tour time length to balance driver workload.

The VRP model will be more complicated when a distributor has to distribute products to many serving retailers that are separated geographically. It needs more time to solve the complicated VRP model. Generally, a distributor has a large number of retailers, thus Cormet et al. (2016) suggest classifying the retailers into several clusters of the distribution area. The clustering retailers' purpose is to simplify a complicated VRP model and reduce the completion time of solving the VRP model (Rautela, et al., 2019). Dondo (2007) also states that in designing a distribution system with a vast distribution area and many retailers, the cluster first-route second algorithm is an appropriate heuristic approach to minimize total distribution cost.

Hiquebran et al. (2010) stated there are two heuristic methods for clustering the distribution area, namely route- first cluster second (RFCS) and cluster-first route-second (CFRS). Similar to Dondo and Cerda (2007), Cormet et al. (2016), and Hiquebran et al. (2010), this paper deals with the cluster first-route second concept to design a distribution system. After clusters are formed in the CFRS concepts, vehicle routes are determined for each cluster independent of each other.

Although Hiquebran et al. (2010), Dondo and Cerda (2007), and also Cormet et al. (2016) apply the CFRS concepts but to determine vehicle routes, they apply different VRP variants. Hiquebran et al. (2010) use the classic vehicle routing problem that have no constraint, while Dondo and Cerda (2007) and also Cormet et al. (2016) use the capacitated vehicle routing problem (CVRP) that consider vehicle capacity constraint. In reality, each retailer has a different time to be able to receive their delivered order or has a different operating time, but whether Hiquebran et al. (2010), Dondo and Cerda (2007), and Cormet et al. (2016) did not consider it in their VRP model. Pérez-rodríguez and Hernández-aguirre (2019) have considered time window (duration time to be able to receive its order) in their VRP model (VRPTW) even though they did not apply CFRS. This paper applies the CFRS and also VRPTW to obtain the optimal vehicle routes.

On the other side, each cluster has many retailers that their order should be fulfilled. It impacts the distributor who will assign several vehicles to fulfill retailers' orders in that cluster. When the distributor usually uses more than one vehicle in a cluster, it is necessary to pay attention to balance the workload among drivers in one cluster. Hiquebran (2010), Cormet et al. (2016), Dondo and Cerda (2007) did not consider it. Therefore, besides applying the cluster firstroute second concept, this paper deals with determining vehicle routes by applying the VRP model that considers time window and a balanced driver's workload. The vehicle route will be determined to maximize the vehicle utility, balance each driver's workload, and minimize the total delivery time. According to the literature review above, the contribution of this study can be briefly shown as proposed model (see Table 1).

\begin{tabular}{|c|c|c|c|c|c|c|}
\hline & $\begin{array}{l}\text { Kritisos } \\
\text { and } \\
\text { loannou } \\
(2010)\end{array}$ & $\begin{array}{c}\text { Hiquebran } \\
\text { et al. } \\
(2010)\end{array}$ & $\begin{array}{c}\text { Dondo } \\
\text { and } \\
\text { Cerda } \\
(2007)\end{array}$ & $\begin{array}{c}\text { Cormet } \\
\text { et al. } \\
(2016)\end{array}$ & $\begin{array}{l}\text { Pérez- } \\
\text { rodríguez } \\
\text { and } \\
\text { Hernández- } \\
\text { aguirre } \\
\text { (2019) }\end{array}$ & $\begin{array}{c}\text { Proposed } \\
\text { model }\end{array}$ \\
\hline $\begin{array}{l}\text { To apply } \\
\text { CFRS }\end{array}$ & & $\sqrt{ }$ & $\sqrt{ }$ & $\sqrt{ }$ & & $\sqrt{ }$ \\
\hline $\begin{array}{l}\text { To } \\
\text { consider } \\
\text { Time } \\
\text { window }\end{array}$ & $\sqrt{ }$ & & & & $\sqrt{ }$ & $\sqrt{ }$ \\
\hline $\begin{array}{l}\text { To } \\
\text { consider } \\
\text { balanced } \\
\text { workload }\end{array}$ & $\begin{array}{c}\sqrt{ } \\
\text { (delivery } \\
\text { load) }\end{array}$ & & & & & $\begin{array}{c}\sqrt{ } \\
\text { (tour time } \\
\text { length) }\end{array}$ \\
\hline
\end{tabular}

\section{RESEARCH FRAMEWORK}

The research framework is to provide a guideline conducting this research systematically. This research framework consists of two stages, the first stage is to develop 
the cluster first route second algorithm, and the second one is to validate the proposed algorithm using a case study. In the first stage, there are two steps of developing the proposed cluster first - route second algorithm, as shown in Figure 1. The first step is to develop a clustering heuristic algorithm to form clusters of distribution. The heuristic algorithm of clustering distribution area is developed based on Comert et al. (2018). Meanwhile, the second step is to develop a vehicle routing problem model by considering the time window and balanced workload (VRPTWBW) for determining the vehicle route in each cluster independent of each other. The VRPTWBW model is developed based on the model VRPTW of Pérez-Rodríguez and HernándezAguirre (2019).

In the second stage, the proposed clustering heuristic algorithm and vehicle routing problem model are applied using numerical data of a distributor of a multi-national company located in East Java. Using the distributor's data, we form the cluster of retailers every day. After forming clusters, we determine each cluster's vehicle route independently for each cluster. In the last part of this research, we compare the company method result (current condition) and the proposed method one.

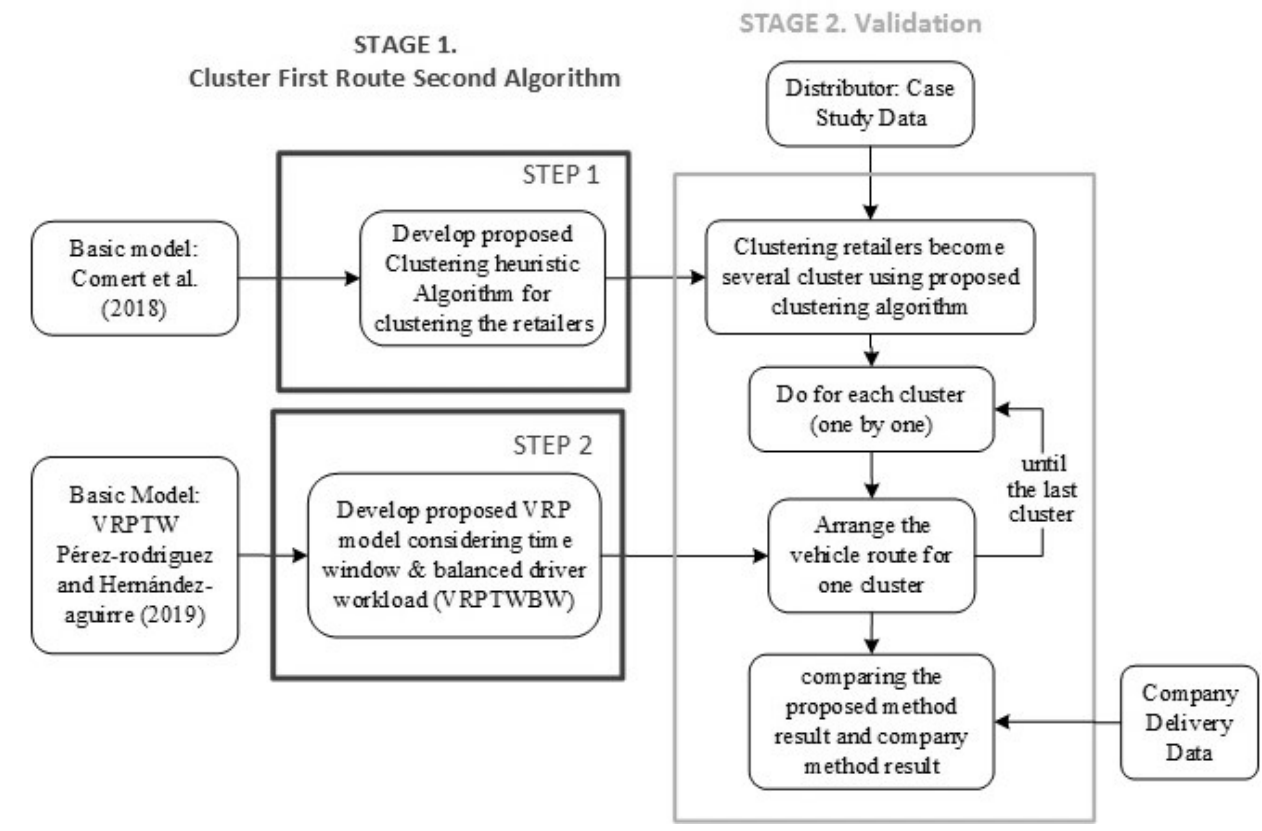

Figure 1 Research framework

\section{DISTRIBUTION SYSTEM DESIGN}

The distribution system in this paper only has one distributor. It distributes its products to a large number of retailers. The location of retailers is separated geographically in a vast distribution area. The conditions cause the VRP model used to become more complicated. Therefore, the cluster first route second concept will be applied to design the distribution system (Figure 2). The first step is to develop heuristic clustering method for clustering the retailers into some clusters. The clustering retailers is to simplify the VRP model and to be able to solve the distribution problem easier. After we classify all retailers becomes several clusters, the next step we develop a vehicle routing problem (VRP) model with considering the time window and balanced driver workload (VRPTWBW).

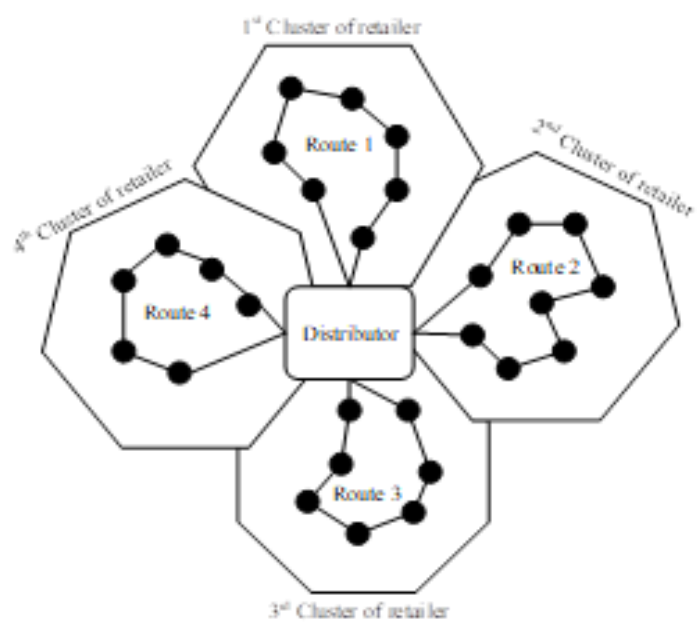

Figure 2 Illustration of retailers clustering and vehicle routing concepts 


\subsection{Retailer Clustering}

In this paper, the retailer's clustering algorithm is developed based on a random clustering algorithm (Comert et al., 2018). Like the random clustering algorithm (Comert et al., 2018), the proposed retailers clustering algorithm aims to maximize the similarity inside the set and minimize the similarity between data sets. The similarity inside and between sets of data can be calculated from the average distance between two retailers. Table 2 contents of the proposed retailers clustering algorithm.

Table 2 Proposed algorithm of retailers clustering

\begin{tabular}{|c|c|}
\hline Step & Activities \\
\hline 1 & $\begin{array}{l}\text { Collect and determine the latitude and longitude of distributor } \\
\text { and retailers that will be served at a particular day }\end{array}$ \\
\hline 2 & $\begin{array}{l}\text { Calculate the distance between retailers and between the } \\
\text { retailer - distributor }\end{array}$ \\
\hline 3 & $\begin{array}{l}\text { Generate cluster by determining which set retailers belong to } \\
\text { according to the shortest distances }\end{array}$ \\
\hline & $\begin{array}{l}\text { a. Choose } k \text { retailers having the shortest distance to } \\
\text { the distributor }\end{array}$ \\
\hline & $\begin{array}{l}\text { b. Classify all retailers that belong to a cluster } \\
\text { according to the shortest distance }\end{array}$ \\
\hline 4 & $\begin{array}{l}\text { Check whether any retailer has a shorter distance to another } \\
\text { cluster, adjust the cluster until no retailer having a shorter } \\
\text { distance to another cluster }\end{array}$ \\
\hline
\end{tabular}

\subsection{Vehicle Routes in Each Cluster of Distribution Area}

After developing the clustering algorithm in the first step, the next step is to develop a VRP model for determining the vehicle route in each cluster. The vehicle route model is developed, taking into account the duration of each retailer's operating time, and balancing the driver's workload. The distributor distributes all products to its retailers in each cluster using its vehicles. The vehicles of each cluster are different. Each retailer has a different duration of operation time and only can be visited by a vehicle. The proposed vehicle routing problem model is developed by considering the balance of each driver workload, the minimum number of vehicles and the total delivery time. The VRPTWBW model is developed based on the VRPTW model developed by Pérez-Rodríguez and Hernández-Aguirre (2019) with the differences as shown in Table 3.

Table 3 Comparison between BRPTW and proposed model

\begin{tabular}{|c|c|c|}
\hline & $\begin{array}{c}\text { VRPTW model of } \\
\text { Pérez-Rodríguez and } \\
\text { Hernández-Aguirre } \\
(2019)\end{array}$ & Proposed model \\
\hline $\begin{array}{l}\text { Objective } \\
\text { function }\end{array}$ & $\begin{array}{l}\text { Minimize total } \\
\text { transportation } \\
\text { distance }\end{array}$ & $\begin{array}{l}\text { - Minimize number of } \\
\text { assigned vehicles } \\
\text { - Minimize total delivery } \\
\text { time } \\
\text { - Balancing the driver's } \\
\text { workload }\end{array}$ \\
\hline \multirow[t]{2}{*}{ Constraint } & Time window & Time window of retailers \\
\hline & & $\begin{array}{l}\text { The total delivery time of } \\
\text { each vehicle has to be less } \\
\text { than the maximum delivery } \\
\text { duration for ensuring } \\
\text { workload balancing of each } \\
\text { vehicle (driver) }\end{array}$ \\
\hline
\end{tabular}

\subsubsection{Mathematical notation}

The mathematical notations that are used in the developing VRPTW model that balancing all of the driver workload (VRPTWBW) consists of Index, parameters/intermediate variable, and decision variables as follows.

Index:

$i, j \quad$ : distribution/retailer location;

$i, j=1$ is distributor and $i, j>1$ are retailers

$v \quad$ : vehicle

$n \quad:$ total number of retailers

$H \quad$ : total number of vehicles

Parameters/intermediate variables:

$K_{v} \quad:$ the capacity of vehicle $v$

$D_{i j} \quad:$ the distance from distributor/retailer location $i$ to retailer/ distributor location $j$

$W_{i v} \quad$ : the total delivery time of distributor/retailer location $i$ using vehicle $v$

$D_{i} \quad:$ the demand of retailer location $i ; \quad i>1$

$A_{i} \quad:$ the earliest time that retailer $i$ is able to receive the load; $i>1$

$B_{i} \quad:$ the latest time that retailer $i$ is able to receive the load $i>1$ or vehicle return to distributor $(i=1)$

$S_{i} \quad:$ the service time at retailer $i ; \quad i>1$

$T_{i j} \quad:$ the transportation time from distributor/retailer $i$ to distributor/retailer $j$

$T_{\max }:$ the maximum delivery duration

$$
\begin{aligned}
& \text { Decision variables: } \\
& Z_{v} \quad=1 \text { if vehicle } v \text { is used and } 0 \text { otherwise } \\
& X_{i j v}=1 \text { if vehicle } v \text { is used to deliver from } \\
& \text { distributor/retailer } i \text { to distributor/retailer } j \text { and } \\
& 0 \text { otherwise }
\end{aligned}
$$

\subsubsection{Mathematical Formulation}

This proposed VRPTWBW model developed based on the VRPTW model of Pérez-rodríguez and Hernándezaguirre (2019) has three objectives. The first objective is to minimize the number of assigned vehicles to deliver the product from a distributor to many retailers $(T V)$. It is formulated by vehicle capacity multiply by $Z v . \mathrm{K} v$ is a parameter for vehicle capacity $v$ that is different for every vehicle. Meanwhile, $\mathrm{Zv}_{\mathrm{v}}$ is a binary variable, a decision variable to indicate whether the vehicle is being used. Thus, when we combine the first objective function and constraint (6), it will maximize the vehicle utility. The second objective is to minimize the total delivery time $(T T)$. The total delivery time is the accumulation of service time and transportation time of all assigned vehicles. The third objective is to balance the workload of all drivers $(T N) . T N$ is the workload of all 
drivers driving an assigned vehicle, so the total working time maximum multiply by $Z v$. The objective functions are as follows.

$$
\begin{array}{ll}
\text { Minimize } & T V=\sum_{v=1}^{H} K_{v} Z_{v} \\
\text { Minimize } & T T=\sum_{v=1}^{H} W_{1 v} \\
\text { Minimize } & T N=\left(\sum_{v=1}^{H} Z_{v}\right) T_{\max }
\end{array}
$$

Several constraints are used to ensure the suitability of the proposed VRPTWBW model and the condition of distribution systems. Constraint (4) ensures that each retailer can only be served by one vehicle. This constraint does not apply to vehicles start from the distributor, so the constraint formula is applied for $i>1$. Meanwhile, each vehicle that arrived from another retailer or distributor is guaranteed by constraint (5) will continue to visit another retailer return to the distributor. The total loads of a vehicle have to be less than its capacity is stated by constraint (6).

$\sum_{j=1}^{n} \sum_{v=1}^{H} X_{i j v}=1 ; \forall i, i \neq 1, j \neq i$

$\sum_{i=1}^{n} X_{i j v}-\sum_{i=1}^{n} X_{j i v}=0 \quad ; \forall j, v j \geq 1$

$\sum_{i=1}^{n} \sum_{j=1}^{n} D_{i} X_{i j v} \leq K_{v} Z_{v} \quad ; \forall v$

Constraint (7) and (8) guarantee that a vehicle always starts from the distributor and returns to the distributor after completing product delivery, where $i, j=1$ is distributor, otherwise retailers.

$\begin{array}{ll}\sum_{i=2}^{n} X_{i 1 v}=Z_{v} & ; \forall v \\ \sum_{j=2}^{n} X_{1 j v}=Z_{v} & ; \forall v\end{array}$

Constraint (9) deals with time window concepts, where a vehicle can only serve retailers during their working or operation time. Operation or working time of retailer $i$ starts at time $A_{i}$ and ends at time $B_{i}$. Constraint (10) states the total time needed in the shipping process until vehicle $v$ arrive at retailer $j$ is summation of time at vehicle $v$ comes at retailer $i$ and transportation time from retailer $i$ to retailer $j$. $M$ is a big number. Meanwhile, if vehicle $v$ starts from distributor $i=1$, so there is no service time at distributor. Therefore, constraint (11) state the total delivery time at retailer $j$ when the vehicle $v$ starts from distributor equal to the transportation time from distributor to retailer $j$. Constraint (13) ensures each vehicle has to be returned to the distributor before the distributor closed. Distributor will be closed at $\mathrm{B}_{1}$. Constraint (14) ensures each vehicle's total delivery time has to be less than the maximum delivery duration for ensuring workload balancing of each vehicle.

$A_{i} \sum_{j=1}^{n} X_{i j v} \leq W_{i v} \leq B_{i} \sum_{j=1}^{n} X_{i j v} ; \forall i, v$

$W_{j v} \geq W_{i v}+S_{i}+T_{i j}-M\left(1-X_{i j v}\right) \quad ;$

$\forall i, j, v \quad i>1, j>1$

$W_{j v} \geq T_{1 j} Z_{v}-M\left(1-X_{1 j v}\right) \quad ; \forall j, v j>1$
$W_{1 v} \geq W_{i v}+S_{i}+T_{i 1} Z_{v}-M\left(1-X_{i 1 v}\right) ;$

$\forall i, v, i>1$

$W_{1 v} \leq B_{1} Z_{v} ; \forall v$

$W_{1 v} \leq T_{\max } \quad ; \forall v$

Constraint (15) and (16) deal with the binary decision variables

$Z_{v} \in 0,1 \quad ; \forall v$

$X_{i j v} \in 0,1 \quad ; \forall i, j, v$

\section{RESULTS AND DISCUSSION}

The proposed clustering heuristic algorithms and VRPTWBW model are applied in one of the multi-national company distributors located in East Java, Indonesia. The distributor distributes various products to a large number of various types of retailers. The distributor classifies its retailers into three types (segments) based on service time duration, and the number of orders. The first type consists of traditional market, retailer and store, the second one is minimarkets, and the last one is supermarkets. Table 4 shows operating time and service time of each type of

\begin{tabular}{|c|c|c|c|}
\hline Types & & $\begin{array}{c}\text { Operating } \\
\text { time }\end{array}$ & Service time \\
\hline 1 & $\begin{array}{l}\text { Traditional market, } \\
\text { retailer, store }\end{array}$ & $\begin{array}{l}08.00 \mathrm{AM}- \\
13.00 \mathrm{PM}\end{array}$ & 15 minutes \\
\hline 2 & Minimarket & $\begin{array}{l}09.00 \mathrm{AM}- \\
14.00 \mathrm{PM}\end{array}$ & 25 minutes \\
\hline 3 & Supermarket & $\begin{array}{l}09.00 \mathrm{AM}- \\
14.00 \mathrm{PM}\end{array}$ & $\begin{array}{l}0.7 \\
\text { minutes } / 0.1465 \mathrm{~m}^{3}\end{array}$ \\
\hline
\end{tabular}
retailers.

Table 4 Operating and service time of each type of retailers

The distributor has 21 vehicles for delivering products to 646 retailers. The twenty-one vehicles can be classified into three types of vehicles. Two vehicles (type 1) have a capacity of $12 \mathrm{~m}^{3}$ per vehicle, and two vehicles (type 2) have a capacity of $6 \mathrm{~m}^{3}$ per vehicle. Meanwhile, 17 vehicles (type 3) have a capacity of $3 \mathrm{~m}^{3}$ per vehicle. Delivering products has to be completed within the duration of retailer operation time. The distributor conducts the clustering and route arrangement every day.

Currently, the distributor forms distribution areas (clusters) based on the retailer type (top priority) and region. With this current clustering method, two retailers of various types are sent in two different vehicles even though their locations are very close. All drivers only receive a list of retailers that must be served, so drivers make their route arrangements without considering the retailers' operation hours. It causes drivers to visit the retailer twice or wait for the store to open to send retailer orders so shipping is inefficient. The current clustering and routing method causes an imbalanced workload of each driver and low vehicle utility. Figure 3 shows the result of clustering on March 5th, 2019. 


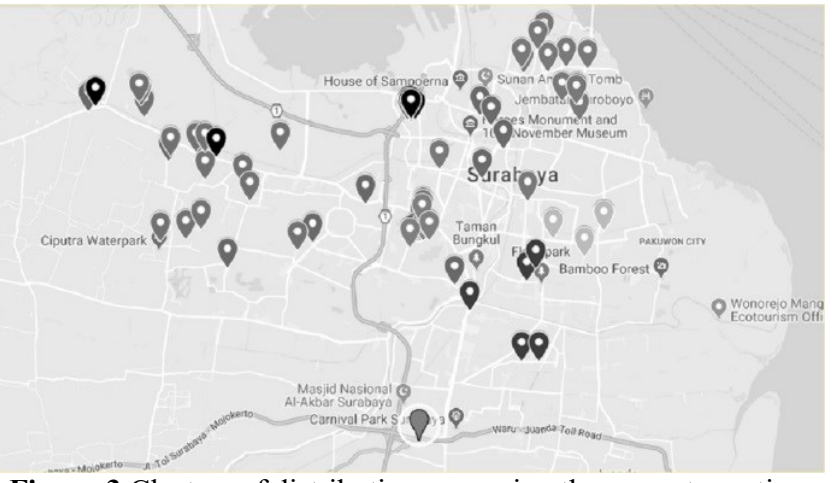

Figure 3 Clusters of distribution area using the current practice

As discussed above, the proposed method consists of two steps, i.e., the clustering method and the routing arrangement. The proposed clustering method is applying to data of retailer's order to the distributor in one day, such as on March $5^{\text {th }}$, 2019. The result of applying the proposed clustering methods is that all retailers that have an order to distributor are classified into three clusters, as shown in Figure 4. The detail of the district area in each cluster as shown in Table 5.

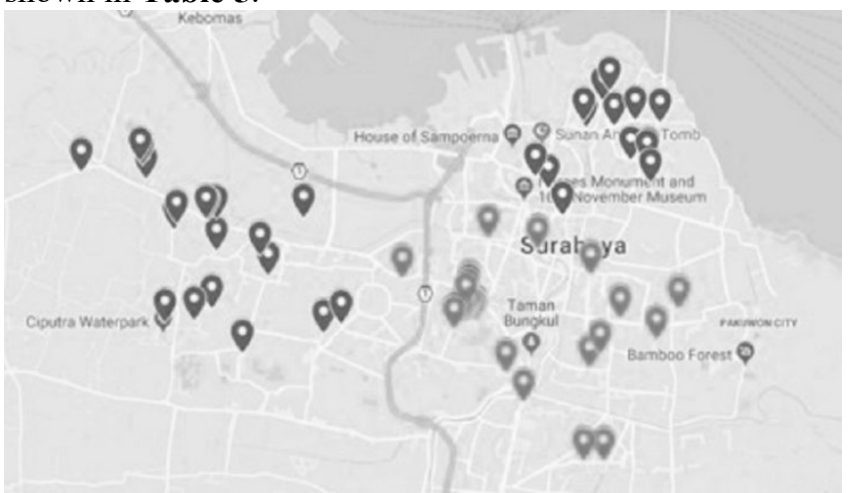

Figure 4 Clusters of distribution area using the proposed method
Table 5 The district area of members in each cluster

\begin{tabular}{cl}
\hline Cluster & \multicolumn{1}{c}{ Distribution area } \\
\hline 1 & $\begin{array}{l}\text { Genteng district, Pabean Cantian district, Kenjeran district } \\
\text { and Tambak Sari district }\end{array}$ \\
2 & $\begin{array}{l}\text { Mulyorejo district, Gubeng district, Sawahan district, } \\
\text { Wonokromo district and Tenggilis Mejoyo district }\end{array}$ \\
3 & $\begin{array}{l}\text { Tandes district, Dukuh Pakis district, Sambikerep district, } \\
\text { Pakal district and Benowo district }\end{array}$ \\
\hline
\end{tabular}

For every day, we form the clusters of distribution area using the proposed clustering algorithm. After forming the distribution area cluster on a particular day, we have to arrange routes in each cluster one by one by implementing the proposed VRPTWBW model. Table 6 shows an example of the outcome of the proposed VRPTWBW model at each cluster on March $5^{\text {th }}, 2019$. We get the number of assigned vehicles and vehicle routes for each cluster every day as well as the number of the served retailer. There are indirect results, i.e., the total loading that a vehicle delivers in one route as well as the vehicle utility, the total delivery distance, and total delivery time $\left(W_{i j}\right)$. With 1 litre of fuel (bio solar), a vehicle can travel an average distance of $6.34 \mathrm{~km}$. The price of 1 litre fuel is amount IDR 5,150, so that the cost of fuel is IDR 812.5 per $\mathrm{km}$. Therefore, we can calculate the total fuel cost for every vehicle on 5/3/2019, as shown in Table 6 .

The workload of each vehicle driver is measured from their total delivery time. For every day, after we have the delivery time of each vehicle, we can get the fastest and the longest delivery time. Based on the fastest and the longest delivery time on a day, we can calculate each vehicle driver's workload gap. Table 7 compares of the delivery time gap, which also means the workload gap between the current practice and the proposed method.

Table 6. The outcome of the proposed VRPTWBW model at each cluster on March $5^{\text {th }}, 2019$

\begin{tabular}{|c|c|c|c|c|c|c|c|c|c|}
\hline Cluster & $\begin{array}{l}\text { Number } \\
\text { of } \\
\text { Retailer }\end{array}$ & $\begin{array}{l}\text { Number } \\
\text { of } \\
\text { Assigned } \\
\text { Vehicle }\end{array}$ & $\begin{array}{l}\text { Vehicle } \\
\text { Number: }\end{array}$ & Route & $\begin{array}{l}\text { Number } \\
\text { Served } \\
\text { Retailer }\end{array}$ & $\begin{array}{l}\text { Total } \\
\text { Loading } \\
\text { (m3) }\end{array}$ & $\begin{array}{l}\text { Total } \\
\text { Delivery } \\
\text { Distance } \\
(\mathrm{km})\end{array}$ & $\begin{array}{l}\text { Total } \\
\text { Delivery } \\
\text { Time } \\
\text { (minutes) }\end{array}$ & $\begin{array}{l}\text { Total } \\
\text { Fuel } \\
\text { Cost } \\
\text { (IDR) }\end{array}$ \\
\hline \multirow{3}{*}{1} & \multirow{3}{*}{28} & \multirow{3}{*}{3} & 1 & $\begin{array}{l}\text { L1-L206-L177-L8-L227-L484-L127- } \\
\text { L464-L119-L616-L1 }\end{array}$ & 9 & 2.35 & 48 & 321 & $38,722.94$ \\
\hline & & & 2 & $\begin{array}{l}\text { L1-L150-L483-L223-L119-L255- } \\
\text { L550-L410-L433-L203-L1 }\end{array}$ & 9 & 2.54 & 45 & 276 & $36,890.75$ \\
\hline & & & 3 & $\begin{array}{l}\text { L1-L149-L60-L528-L345-L531-L198- } \\
\text { L548-L526-L629-L589-L1 }\end{array}$ & 10 & 1.46 & 54 & 318 & $43,901.00$ \\
\hline \multirow{3}{*}{2} & \multirow{3}{*}{20} & \multirow{3}{*}{2} & 4 & $\begin{array}{l}\text { L1-L458-L204-L452-L328-L181- } \\
\text { L175-L449-L360-L627-L257-L642-L1 }\end{array}$ & 11 & 0.56 & 66 & 311 & $53,847.63$ \\
\hline & & & & & & & & & \\
\hline & & & 5 & $\begin{array}{l}\text { L1-L518-L213-L130-L522-L314- } \\
\text { L362-L344-L418-L415-L1 }\end{array}$ & 9 & 1.30 & 68 & 338 & $55,235.38$ \\
\hline 3 & 14 & 1 & 6 & $\begin{array}{l}\text { L1-L438-L299-L417-L200-L634- } \\
\text { L461-L447-L474-L129-L39-L195- } \\
\text { L432-L412-L520-L1 }\end{array}$ & 14 & 0.99 & 70 & 376 & $57,096.81$ \\
\hline
\end{tabular}


Table 7 Comparing the gap of workload

\begin{tabular}{|c|c|c|c|c|c|c|c|}
\hline \multirow{3}{*}{$\begin{array}{c}\text { Date } \\
\text { (year 2019) }\end{array}$} & \multicolumn{6}{|c|}{ Gap of workload } & \multirow{3}{*}{ Reduction (\%) } \\
\hline & \multicolumn{3}{|c|}{ Current Practice } & \multicolumn{3}{|c|}{ Proposed } & \\
\hline & $\begin{array}{l}\text { The fastest } \\
\text { time (hours) }\end{array}$ & $\begin{array}{l}\text { The longest } \\
\text { time (hours) }\end{array}$ & Gap (hours) & $\begin{array}{l}\text { The fastest } \\
\text { time (hours) }\end{array}$ & $\begin{array}{l}\text { The longest } \\
\text { time (hours) }\end{array}$ & Gap (hours) & \\
\hline March $5^{\text {th }}$ & 4.83 & 6.85 & 2.02 & 4.6 & 6.27 & 1.67 & $17 \%$ \\
\hline March $6^{\text {th }}$ & 4.08 & 6.83 & 2.75 & 4.25 & 6.35 & 2.1 & $24 \%$ \\
\hline March $8^{\text {th }}$ & 4.92 & 6.92 & 2 & 5.67 & 7.02 & 1.35 & $33 \%$ \\
\hline March $9^{\text {th }}$ & 3.67 & 6.33 & 2.67 & 5.24 & 6.22 & 0.98 & $63 \%$ \\
\hline March $11^{\text {th }}$ & 4 & 7.17 & 3.17 & 3.82 & 5.66 & 1.84 & $42 \%$ \\
\hline March $12^{\text {th }}$ & 4.33 & 6.25 & 1.92 & 4.73 & 6.21 & 1.48 & $23 \%$ \\
\hline March $13^{\text {th }}$ & 4.67 & 7.33 & 2.67 & 4.95 & 5.91 & 0.96 & $64 \%$ \\
\hline March $14^{\text {th }}$ & 4.67 & 7.67 & 3 & 4.09 & 6.83 & 2.75 & $8 \%$ \\
\hline March $15^{\text {th }}$ & 4.5 & 7.87 & 3.37 & 4 & 7.27 & 3.26 & $3 \%$ \\
\hline March $16^{\text {th }}$ & 4.17 & 6.5 & 2.33 & 4.28 & 6.18 & 1.9 & $18 \%$ \\
\hline Average & \multicolumn{4}{|c|}{2.59} & \multicolumn{2}{|c|}{1.83} & $29 \%$ \\
\hline
\end{tabular}

Table 7 shows that the proposed clustering algorithm and VRPTWBW model can reduce the average driver workload gap by around $29 \%$. The company routing methods result in the average driver workload amount of 2.59 hours, while the proposed VRPTWBW results in 1.83 hours. It means the proposed clustering algorithm and routing method results in a more balanced workload.

Although the average workload of drivers using the proposed method is 1.83 , if we analyze the driver workload gap per day in more detail, the driver workload gap is measured by the difference of the longest and fastest delivery time. The driver workload gap ranges from 0.96 hours to 3.26 hours. There were two days where the workload gap was more than 2.5 hours or $50 \%$ greater than the average. If we look again at Table 5, each vehicle's total delivery time is not in line with the vehicle's load carried (vehicle utility) but in line with the total delivery distance. Thus, we can conclude that the total vehicle delivery distance is not only influenced by the number of retailers served by a vehicle but also the retail distribution area (Table 5). Therefore, future research needs to be carried out by developing the clustering retailer algorithm that considers the retailers' distance and the number of served retailers, so the driver workload is more balanced.

Vehicle utility is calculated from the ratio of total loading of the vehicle and the vehicle capacity. Table 8 shows the average vehicle utility per day using both the company method and the proposed method. The average vehicle utility using current practice is $30 \%$, while the average vehicle utility using the proposed method becomes $43 \%$. The proposed methods consisted of the clustering algorithm, and the VRPTWBW model can increase vehicle utility by around $44 \%$. Although the increase in vehicle utility using the proposed method is around $44 \%$, the average vehicle utility is still low. We pay attention to the average total delivery time per day ranging between 4 hours until 6 hours. It is still able to make an improvement to increase vehicle utility in the future.

Table 8 Comparing the vehicle utility

\begin{tabular}{|c|c|c|c|}
\hline \multirow{2}{*}{$\begin{array}{c}\text { Date } \\
\text { (year 2019) }\end{array}$} & \multicolumn{2}{|c|}{ Average vehicle utility } & \multirow{2}{*}{$\begin{array}{c}\text { Increment } \\
(\%)\end{array}$} \\
\hline & Current practice & Proposed & \\
\hline March $5^{\text {th }}$ & $37 \%$ & $51 \%$ & $38 \%$ \\
\hline March $6^{\text {th }}$ & $30 \%$ & $51 \%$ & $67 \%$ \\
\hline March $8^{\text {th }}$ & $23 \%$ & $35 \%$ & $50 \%$ \\
\hline March $9^{\text {th }}$ & $37 \%$ & $53 \%$ & $42 \%$ \\
\hline March $11^{\text {th }}$ & $15 \%$ & $22 \%$ & $50 \%$ \\
\hline March $12^{\text {th }}$ & $43 \%$ & $49 \%$ & $14 \%$ \\
\hline March $13^{\text {th }}$ & $33 \%$ & $49 \%$ & $50 \%$ \\
\hline March $14^{\text {th }}$ & $21 \%$ & $31 \%$ & $50 \%$ \\
\hline March $15^{\text {th }}$ & $23 \%$ & $34 \%$ & $50 \%$ \\
\hline March $16^{\text {th }}$ & $35 \%$ & $51 \%$ & $46 \%$ \\
\hline Average & $30 \%$ & $43 \%$ & $44 \%$ \\
\hline
\end{tabular}

Table 9 shows the comparison between the total transportation cost of current practice and the proposed method and the cost saving. The total transportation cost consists of the total fuel cost and the fixed cost of the vehicle. Transportation cost is driven by assigned vehicles. In contrast, the assigned vehicle is driven by fulfilling retailer order (demand) that have to be delivered, vehicle utility, time window (range of retailer operating time), and the balanced driver workload. Due to the reduced number of assigned vehicles, the proposed methods can reduce the transportation cost by around $23.84 \%$. In this paper, reducing the transportation cost is the impact of minimizing the assigned vehicles. For the future study, the transportation cost can be considered to become the objective function. 
Table 9 Comparing the total transportation cost and the cost saving

\begin{tabular}{|c|c|c|c|c|c|c|c|c|}
\hline \multirow{3}{*}{$\begin{array}{c}\text { Date } \\
\text { (year 2019) }\end{array}$} & \multicolumn{3}{|c|}{ Current } & \multicolumn{3}{|c|}{ Proposed } & \multirow{3}{*}{ (IDR) } & \multirow{3}{*}{$\begin{array}{c}\text { Cost saving } \\
(\%)\end{array}$} \\
\hline & \multicolumn{2}{|c|}{ Type vehicle } & \multirow[t]{2}{*}{ Total cost } & \multicolumn{2}{|c|}{ Type Vehicle } & \multirow[t]{2}{*}{ Total cost } & & \\
\hline & $\mathrm{C}$ & B & & $\mathrm{C}$ & B & & & \\
\hline March $5^{\text {th }}$ & 7 & 1 & $4,890,221.50$ & 6 & 0 & $3,553,816.50$ & $1,336,405.00$ & $27.33 \%$ \\
\hline March $6^{\text {th }}$ & 6 & 2 & $4,915,134.50$ & 6 & 0 & $3,560,687.81$ & $1,354,446.69$ & $27.56 \%$ \\
\hline March $8^{\text {th }}$ & 7 & 1 & $4,869,096.50$ & 6 & 0 & $3,575,758.88$ & $1,293,337.63$ & $26.56 \%$ \\
\hline March $9^{\text {th }}$ & 8 & 1 & $5,265,908.50$ & 7 & 0 & $4,134,827.13$ & $1,131,081.38$ & $21.48 \%$ \\
\hline March $11^{\text {th }}$ & 7 & 1 & $4,782,971.50$ & 6 & 0 & $3,532,596.44$ & $1,250,375.06$ & $26.14 \%$ \\
\hline March $12^{\text {th }}$ & 6 & 1 & $4,186,284.50$ & 7 & 0 & $4,148,382.06$ & $37,902.44$ & $0.91 \%$ \\
\hline March $13^{\text {th }}$ & 7 & 1 & $4,895,909.00$ & 6 & 0 & $3,558,353.50$ & $1,337,555.50$ & $27.32 \%$ \\
\hline March $14^{\text {th }}$ & 7 & 1 & $4,838,221.50$ & 6 & 0 & $3,537,369.88$ & $1,300,851.63$ & $26.89 \%$ \\
\hline March $15^{\text {th }}$ & 7 & 1 & $4,730,159.00$ & 6 & 0 & $3,547,487.13$ & $1,182,671.88$ & $25.00 \%$ \\
\hline March $16^{\text {th }}$ & 7 & 1 & $4,813,846.50$ & 6 & 0 & $3,549,463.13$ & $1,264,383.38$ & $26.27 \%$ \\
\hline Total & & & $48,187,753.00$ & & & $36,698,742.44$ & $11,489,010.56$ & $23.84 \%$ \\
\hline
\end{tabular}

\section{CONCLUSION}

The proposed method is developed based on the concepts of cluster first - route second. Therefore, the proposed method consists of two steps, and the first is to develop clustering algorithm based on the distance of retailers for classifying all retailers into several clusters. The second step is to develop VRPTWBW model for determining the vehicle routes in each cluster formed in step one.

The results of applying the proposed methods in a distributor are as follow. There are three clusters formed, the proposed method can reduce the average of driver workload gap around $29 \%$, increase the average of vehicle utility around $44 \%$ and reduce the total transportation cost around $23.84 \%$.

Although the proposed methods have increased the distribution performance, there are some potentials for future research. It is to develop the clustering retailer algorithm that considers the retailers' distance and the number of served retailers in each cluster to establish a more balanced workload. We will also consider the minimum utility vehicle used to improve vehicle utility and to consider transportation cost to become an objective function.

\section{ACKNOWLEDGEMENT}

The authors would like to thank the Ministry of Research, Technology and Higher Education, Republic of Indonesia, supported and provided funding for this research through the applied research grant of university excellence (PTUPT, Kemenristekdikti).

\section{REFERENCES}

Baldacci, R., Mingozzi, A., and Roberti, R. (2012). Recent exact algorithms for solving the vehicle routing problem under capacity and time window constraints. European Journal of Operational Research 218, pp. 1-6.

Braekers, K., Ramaekers, K. and Van Nieuwenhuyse, I. (2016). The vehicle routing problem: state of the art classification and review. Computers and Industrial Engineering 99, pp. 300-313.
Chen, X. (2018). An improved efficient algorithm for time dependent vehicle routing. Operation and Supply Chain Management 11 (2), pp. 55-65.

Chopra, S. (2019). Supply chain management: strategy, planning \& operation 7th Ed. USA: Pearson Education.

Comert, S.E., Yazgan, H.R., Kır, S. and Yener, F. (2018). A cluster first-route second approach for a capacitated vehicle routing problem: a case study. International Journal of Procurement Management 11 (4), pp. 399-419.

Cortes, J.D. and Suzuki, Y. (2020). Vehicle routing with consolidation. International Journal of Production Economics 227, pp. 1-13.

Daneshzand, F. (2011). The vehicle-routing problem. In Farahani, R. Z., Rezapour, S. and Kardar, L. (Eds.) Logistics operations and management: concepts and models (pp. 127-153). London: Elsevier Inc.

Das, K., Lashkari, R.S. and Khan, A.R. (2021). A humanitarian logistics-based planning for rescue and relief operation after a devastating fire accident. Operations and Supply Chain Management 14 (1), pp. 51-61.

Dondo, R. and Cerda, J. (2007). A cluster-based optimization approach for the multi-depot heterogeneous fleet vehicle routing problem with time windows. European Journal of Operational Research 176, pp. 1478-1507.

Eksioglu, B., Vural, A.V. and Reisman, A. (2009). The vehicle routing problem: A taxonomic review. Computers \& Industrial Engineering 57, pp. 14721483.

El-Sherbeny, N.A. (2010). Vehicle routing with time windows: an overview of exact, heuristic and metaheuristic methods. Journal of King Saud University-Science 22 (3), pp. 123-131.

Ghiani, G., Laporte. G. and Musmanno, R. (2004). Introduction to logistics systems planning and control. UK: John Wiley \& Sons, Ltd.

Ghiani, G., Laporte. G. and Musmanno, R. (2013). Introduction to logistics systems management, 2nd edition. UK: John Wiley \& Sons, Ltd.

Goetschalckx, M. (2011). Supply chain engineering. In Hillier, F. S. and Price, C. C. (Eds), International 
series in operations research and management science 161. New York: Springer.

Hiquebran, D.T., Alfa, A.S. Shapiro, J.A. and Gittoes, D.H., (1993). A revised simulated annealing and cluster-first route-second algorithm applied to the vehicle routing problem. Engineering Optimization 22 (2), pp. 77-107.

Jin, J., Crainic, T.G., and Lokketangen, A. (2014). A cooperative parallel metaheuristic for the capacitated vehicle routing problem. Computers \& Operations Research 44, pp. 33-41.

Kritikos, M. N. and loannou, G. (2010). The balanced cargo vehicle routing problem with time windows. International Journal Production Economies 123 (1), pp. 42-51.

Lahyani, R., Khemakhem, M., and Semet, F. (2015). Rich vehicle routing problems: from a taxonomy to a definition. European Journal of Operational Research 241, pp. 1-14.

Laporte, G., Nobert, Y. and Taillefer, S. (1988). Solving a family of multi-depot vehicle routing and locationrouting problems. Transportation Science 22 (3), pp.161-172.

Lee, T. R. and Ueng, J. H. (1999). A Study of vehicle routing problems with load-balancing. International Journal of Physical Distribution and Logistics Management 29 (10), pp. 646-657.

Lei, H., Laporte, G., and Guo, B. (2011). The capacitated vehicle routing problem with stochastic demands and time windows. Computers \& Operations Research 38 (12), pp. 1775-1783.

Liao, T.Y., Hu, T.Y., and Wu, Y.W. (2017). A timedependent vehicle routing algorithm for medical supplies distribution under emergency. Operations and Supply Chain Management 10 (3), pp. 161-169.
Matl, P., Hartl, R. F., \& Vidal, T. (2017). Workload Equity in VRPs: A Survey and Analysis. Transportation Science, 52(2), pp. 239-260.

Mancini, S., Gansterer, M. and Hartl, R.F. (2021). The collaborative consistent vehicle routing problem with workload balance. European Journal of Operational Research 293, pp. 955-965

Miranda, D.M., and Conceição, S.V. 2016). The vehicle routing problem with hard time windows and stochastic travel and service time. Expert Systems With Applications 64, pp. 104-116.

Neves-Moreira, F., Amorim, P., Guimarães, L. and Almada-Lobo, B. (2016). A long-haul freight transportation problem: synchronizing resources to deliver requests passing through multiple transhipment locations. European Journal of Operation Research 248 (2), pp. 487-506.

Pérez-rodríguez, R. and Hernández-aguirre, A. (2019). A hybrid estimation of distribution algorithm for the vehicle routing problem with time windows. Computers and Industrial Engineering 130, pp. 75 96.

Rautela, A., Sharma, S.K. and Bhardwaj, P. (2019). Distribution planning using capacitated clustering and vehicle routing problem: a case of Indian cooperative dairy. Journal of Advances in Management Research 16 (5), pp. 781-795.

Ravindran, A.R. and Warsing Jr., D.P. (2013). Supply chain engineering: models and applications. New York: Taylor \& Francis Group.

Toth, P. and Vigo, D. (2002). Model, relaxations and exact approaches for the capacitated vehicle routing problem. Discrete Applied Mathematics 123, pp. 487-512.

\begin{abstract}
Amelia Santoso is an Associate Professor of Industrial Engineering at the University of Surabaya, Indonesia. She received her Master's and Ph.D. degree in Industrial Engineering from Institut Teknologi Bandung (ITB), Bandung, Indonesia, and her Bachelor's degree in Statistics from Institut Teknologi Sepuluh Nopember (ITS) Surabaya, Indonesia. Her research interests are production, distribution, transportation systems; supply chain engineering; and humanitarian logistics in disaster operations and management.
\end{abstract}

Joniarto Parung is currently a Professor of Supply Chain Management at the Department of Industrial Engineering, University of Surabaya, Indonesia. He received his Ph.D. from Design Manufacture and Engineering Management, University of Strathclyde, Glasgow, UK. His research interests include supply chain management, smart supply chain, sustainable supply chain, and humanitarian logistics.

Dina Natalia is an Associate Professor of Industrial Engineering at the University of Surabaya, Indonesia. She received her Master's degree in Industrial Engineering from the National University of Singapore and her Bachelor's degree in Physic Engineering from Institut Teknologi Sepuluh Nopember (ITS) Surabaya, Indonesia. Her research interests are in container terminal operations, supply chain engineering, and disaster operations and management.

Winardi is an industrial practitioner, and he obtained a bachelor's degree in Industrial Engineering from the University of Surabaya, Indonesia. His research interests include transportation and distribution systems, Vehicle routing optimization, and modeling. 